
creativecommons.org/licenses/by/3.0/), which permits unrestricted re-use, distribution, and reproduction in any medium, provided the original work is properly cited.

\title{
Plant-rich mixed meals based on Palaeolithic diet principles have a dramatic impact on incretin, peptide YY and satiety response, but show little effect on glucose and insulin homeostasis: an acute-effects randomised study
}

\author{
H. Frances J. Bligh ${ }^{1 *}$, Ian F. Godsland ${ }^{2}$, Gary Frost ${ }^{3}$, Karl J. Hunter ${ }^{1}$, Peter Murray ${ }^{1}$, Katrina MacAulay ${ }^{1}$, \\ Della Hyliands ${ }^{1}$, Duncan C. S. Talbot ${ }^{1}$, John Casey ${ }^{1}$, Theo P. J. Mulder ${ }^{4}$ and Mark J. Berry ${ }^{1}$ \\ ${ }^{1}$ Unilever RED, Colworth Science Park, Sharnbrook, Bedfordshire MK44 1LQ, UK \\ ${ }^{2}$ Diabetes, Endocrinology and Metabolic Medicine Group, Division of Diabetes Endocrinology and Metabolism, Faculty of \\ Medicine, Imperial College London, Norfolk Place, London W2 1PG, UK \\ ${ }^{3}$ Nutrition and Dietetic Research Group, Division of Diabetes Endocrinology and Metabolism, Faculty of Medicine, Imperial \\ College London, DuCane Road, London W12 ONN, UK \\ ${ }^{4}$ Unilever RED, Clinicals, Olivier van Noortlaan 121, Vlaardingen, The Netherlands
}

(Submitted 15 May 2014 - Final revision received 30 October 2014 - Accepted 10 November 2014)

\begin{abstract}
There is evidence for health benefits from 'Palaeolithic' diets; however, there are a few data on the acute effects of rationally designed Palaeolithic-type meals. In the present study, we used Palaeolithic diet principles to construct meals comprising readily available ingredients: fish and a variety of plants, selected to be rich in fibre and phyto-nutrients. We investigated the acute effects of two Palaeolithic-type meals (PAL 1 and PAL 2) and a reference meal based on WHO guidelines (REF), on blood glucose control, gut hormone responses and appetite regulation. Using a randomised cross-over trial design, healthy subjects were given three meals on separate occasions. PAL2 and REF were matched for energy, protein, fat and carbohydrates; PAL1 contained more protein and energy. Plasma glucose, insulin, glucagon-like peptide-1 (GLP-1), glucose-dependent insulinotropic peptide (GIP) and peptide YY (PYY) concentrations were measured over a period of $180 \mathrm{~min}$. Satiation was assessed using electronic visual analogue scale (EVAS) scores. GLP-1 and PYY concentrations were significantly increased across $180 \mathrm{~min}$ for both PAL1 $(P=0.001$ and $P<0.001)$ and PAL2 $(P=0.011$ and $P=0.003)$ compared with the REF. Concomitant EVAS scores showed increased satiety. By contrast, GIP concentration was significantly suppressed. Positive incremental AUC over $120 \mathrm{~min}$ for glucose and insulin did not differ between the meals. Consumption of meals based on Palaeolithic diet principles resulted in significant increases in incretin and anorectic gut hormones and increased perceived satiety. Surprisingly, this was independent of the energy or protein content of the meal and therefore suggests potential benefits for reduced risk of obesity.
\end{abstract}

Key words: Incretin: Diet: Glucose homeostasis

Rising global levels of obesity and type 2 diabetes (T2D) are major public health problems facing the human race and are putting considerable load on healthcare resources. Obesity and $\mathrm{T} 2 \mathrm{D}$ are closely interlinked, with the rise in T2D mapping the rise in obesity ${ }^{(1)}$. Over the centuries, the diet consumed by humans has changed from an energy-dilute diet based on fruit, vegetables and fish to an energy-dense diet of processed foods rich in starch, sugar and fat. The proposal that man currently eats a diet to which, in evolutionary terms, he is poorly adapted was first put forward in 1975 by Voegtlin ${ }^{(2)}$, a concept taken up and developed by Boyd-Eaton \& Konner ${ }^{(3)}$ in 1985.
They suggested that what they termed the Palaeolithic diet (i.e. diet of humans before the Neolithic Revolution) was likely to be high in protein and rich in plant matter, while containing no cereals or dairy products, and proposed this as a nutrition strategy better fitted for the human genome. It would also be expected that such a diet, while involving cooking, would have less in the way of processing than is found in modern foods. This is based, in part, on the theory that, as farming only resulted in the consumption of dairy and cereal products (that were themselves dependent on more intensive processing) in the past 7000-10000 years,

\footnotetext{
Abbreviations: + iAUC, positive incremental AUC; EVAS, electronic visual analogue scale; $G_{\mathrm{b}}$, glucose basal; GIP, glucose-dependent insulinotropic peptide; GLP-1, glucagon-like peptide-1; $I_{\mathrm{b}}$, insulin basal; PAL1, Palaeolithic meal 1; PAL2, Palaeolithic meal 2; PYY, peptide YY; REF, reference meal; T2D, type 2 diabetes.
} 
man has not had sufficient time to evolve to such a drastic change in diet. Recent studies on the health benefits of Palaeolithic-style diets have been conducted over periods of weeks ${ }^{(4,5)}$ or months ${ }^{(6-8)}$, and found benefits including reduced blood pressure and cholesterol levels and improved glucose tolerance. There is also evidence to suggest improved satiety leading to weight loss for this form of $\operatorname{diet}^{(9)}$. However, to date, little mechanistic insight into these observations has been offered, although the reported improvement of glucose tolerance suggests a link to glycaemic control. To investigate this, we designed two test meals (Palaeolithic meal 1 (PAL1) and Palaeolithic meal 2 (PAL2)) to test our hypothesis that acute effects on carbohydrate metabolism of this diet was a key element of the health benefits so far observed, taking as a starting point the basic principles of a Palaeolithic diet but using modern food ingredients. Diets used in previous studies, with emphasis on salad and vegetable preparation 'from scratch' would have long-term acceptability and compliance issues for the modern-day consumer. Therefore, we decided to develop Palaeolithic diet principles while using modern foods and meal design, but keeping processing to a minimum to maintain plant structures. These mixed meals therefore consisted of fruit, vegetables and protein, but lacked starchy cereals, dairy products, legumes, and refined fats and sugars. In addition, although cooking of food was required, the plant material chosen for the study was used fresh, where possible, and minimal processing in terms of the plant structure was used. These were compared with a reference meal (REF) based broadly on the current WHO nutritional guidelines. Many Palaeolithic diets propose a high level of animal protein, and to separate the possible effects of this from the fruit and vegetable component, PAL2 was designed to have a lower level of protein that matched that of the REF, while PAL1 was designed to have the higher level of protein used by other authors, but with the same level of carbohydrate.

We investigated the acute effects of the consumption of these Palaeolithic-inspired meals on metabolism. Specifically, we investigated the parameters that are thought to influence glucose control including indices of insulin sensitivity and secretion, as these are the features of meals that would be expected to have a low glycaemic index, based on the highly unprocessed plant matter and low starch content. In addition, we explored satiety, gut hormone and incretin responses. The gastric hormones studied included glucagon-like peptide-1 (GLP-1) and glucose-dependent insulinotropic peptide (GIP) that play a role in the insulin response, while GLP-1 and peptide YY (PYY) are involved in satiety response and ileal brake mechanism. It was hypothesised that Palaeolithic meals would have a lower glucose response, and that this would be indicated by altered incretin and satiety responses.

\section{Materials and methods}

The present study was conducted according to the guidelines laid down in the Declaration of Helsinki, and all procedures involving human subjects were approved by Independent Ethics Committee (REC reference 11/LO/0911) NRES Committee South East Coast, Kent, UK. Written and informed consent was obtained from all volunteer subjects. The present trial was registered at www.clinicaltrials.gov, as 'Glycemic Response After Palaeolithic-type Meals' (ID no. NCT01418573).

\section{Meal development}

The REF was designed based on macronutrient proportions from WHO Technical report $880^{(10)}$, and contained protein, fruit and vegetables as well as cereals. Polished (but not parboiled) rice was chosen as a carbohydrate/cereal component. Rice was used, as opposed to other plant starch materials such as pasta, as minimal processing of the plant material occurs before cooking and the rice could all be sourced from a single batch for consistency throughout the trial.

PAL1 was based on estimated range ratios for protein and fat that are typical of Hunter-Gatherers and contained no cereals or dairy products, as updated recently ${ }^{(11)}$, although carbohydrate was slightly higher to allow matching across all three meals.

PAL2 was made with identical plant-based ingredients to PAL1, but normalised to the REF for fat, protein and energy in addition to available carbohydrates, by changing the fish, nut and strawberry content.

All the three test meals were normalised to contain $50 \mathrm{~g}$ of available carbohydrates by calculation from literature values (available at http://nutritiondata.self.com).

Full ingredients for all the test meals are presented in Table 1. Ingredients for the PAL meals were selected according to the previously defined Palaeolithic principles, in that they included a wide range of fruit and vegetables, but no cereals or dairy products ${ }^{(3)}$. Additionally all the plant-based ingredients were selected as rich in polyphenols (e.g. strawberries ${ }^{(12)}$ ) and fibre, as we hypothesise that these would be higher in ancestral plants because of their broader genetic variation $^{(13)}$. As necessity of supply meant that the plant material used was from commercial sources and, therefore, not likely to be as high in phytochemicals due to selective breeding, phytochemical levels were boosted by the addition of cinnamon ${ }^{(14)}$ and capers ${ }^{(15)}$. Fish was used as a protein source across all the three test meals, although PAL1 contained white fish as this enabled boosting of protein levels while keeping the fat content of the meal constant with the other two.

Meals were prepared and cooked in single batches and frozen before the start of the study, with ingredients all sourced at the same time. For the Palaeolithic meals (PAL1 and PAL2), the fruit and vegetable content was batch stirfried as individual portions. Other components such as fish and carrots were precooked and frozen as individual portions to be added on the morning of the study. All food was reheated on the morning of the study and served hot, with the exception of rice for the REF, which was cooked fresh each morning. Samples of each meal were submitted for nutritional analysis (Leatherhead Food Research). To match the carbohydrate content of the REF and to allow for a possible variation between the two types of rice and cooking methods, a sample of long-grain rice bought for the study was cooked in a rice cooker, according to the manufacturer's instructions, 
randomised according to a Williams design within each cohort. Allocation to cohort and of treatment was carried out by an independent statistician who was not involved in the assessment of the study. The investigator and outcome assessor were blinded, while due to the nature of the test material, caregiver and subjects were not blinded. Treatments were pre-randomised to subject numbers. Subjects were assigned a number based on the sequence of entering the study. Subjects were only aware that they were being asked to eat three different meals, no expectations regarding their response to the meals were suggested, and they were unaware as to which meal was reference and which was experimental.

\section{Metabolic study protocol}

The intervention elements of the study were carried out at the clinical investigation unit of Leatherhead Food Research (Leatherhead, Surrey, England), which recruited participants in July and August 2011 and assigned them to cohorts. Statistical analysis was performed by Unilever Discover, which were initially blinded to the treatments. Volunteers were asked to fast for $12 \mathrm{~h}$ before attending the research unit. All volunteers visited the research unit at 09.00 hours between 19 August and 28 September 2011. On arrival, a cannula was placed in the forearm of all volunteers and baseline measurements were taken. Immediately following this, subjects were fed the meal which they were told to consume within $20 \mathrm{~min}$. If they took longer than 20 min to finish the meal, subjects were excluded at the blind review. Subjects were served the meals in individual booths and were not allowed to talk. Subjects were fed at $10 \mathrm{~min}$ intervals for ease of sample taking later.

\section{Study measurements}

During each of the three interventions, sixteen venous blood samples were collected via an indwelling cannula (eight samples of 3 and $5 \mathrm{ml}$ for gut hormones and glucose) into BD-P800 ${ }^{\mathrm{TM}}$ blood (B\&D) collection tubes containing a cocktail of protease, esterase and DPP-IV inhibitors and eight samples of 3 and $5 \mathrm{ml}$ for insulin into heparinised tubes. Samples were collected at $-15,15,30,45,60,90,120$ and $180 \mathrm{~min}$ relative to the start of consumption of the meal.

Venous plasma glucose analysis as a primary outcome was conducted on a Horiba ABX Pentra 400 Clinical Chemistry Analyser using the commercially available Glucose PAP CP Kit (reference no. A11A01668; Horiba Medical).

Insulin (primary outcome) in heparinised plasma was analysed using an immulite 2000 Systems analyser, a solid-phase enzyme-labelled chemiluminescent immunometric assay kit ('ECLIA' for Roche Elecsys 1010/2010 immunoassay analyser) from Roche Diagnostics GmbH. Its reportable range was $13.89-2083.5 \mathrm{pmol} / 1$ with sensitivity $13.89 \mathrm{pmol} / \mathrm{l}$.

Exploratory analysis of gut hormones was performed on blood plasma using MILLIPLEX MAP Human Gut Hormones (HGT-68K 08), EMD Millipore Corporation. This is a multiplex assay kit used to measure ghrelin, leptin, GIP, GLP -1, amylin (active and total), pancreatic polypeptide, PYY and Insulin in human plasma. GLP-1 was repeated by a commercially available ELISA assay (code 27784 ; IBL Limited), as the MILLIPLEX MAP system failed to give sufficient sensitivity for this analyte.

Secondary outcome ratings of appetite: feelings (how hungry are you? how full are you? and how strong is your desire to eat?) were scored using a mark on 60-mm scales using EVAS

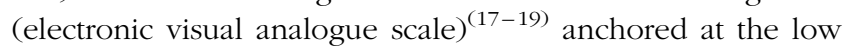
end with the most negative or lowest-intensity feelings (e.g. extremely unpleasant, not at all), and with opposing terms at the high end (e.g. extremely pleasant, very high, extreme). Volunteers were asked to indicate on a line which place on the scale best reflects their feelings at that moment. Scores were collected so that they could not be used as a further reference for later scores. Volunteers completed the questionnaires pre- and at regular intervals post-consumption $(-20,10,25$, $40,55,85,115,175 \mathrm{~min}$ relative to the start of the meal).

Ratings on physical discomfort (headache, stomach discomfort, bloating, heartburn, nausea and belching) were made on a 4-point scale $(0=$ not, $1=$ little, $2=$ moderate and $3=$ much $)$ or on a line scale at baseline $(-20 \mathrm{~min})$ and at 55, 115 and 175. Ratings of taste and liking (e.g. general acceptance, mouth feel acceptance, taste acceptance, smell acceptance) were filled on an EVAS 10 min after consumption of the test product ${ }^{(18,19)}$.

Ratings of liking (overall, smell, taste and mouth feel) were scored by means of a mark on $60 \mathrm{~mm}$ scales using the EVAS at $15 \mathrm{~min}$.

There were no reports of serious adverse events. However, three subjects each reported a mild and transient gastrointestinal discomfort, of which two were considered to be unlikely to be related to the study and the remaining (PAL1 consumption) was possibly related.

\section{Statistical analysis}

Glucose and insulin concentrations were characterised in terms of the basal and preprandial concentrations $\left(G_{\mathrm{b}}\right.$ and $I_{\mathrm{b}}$, respectively) and, postprandially, the incremental area under the concentration profile for $120 \mathrm{~min}$ (for glucose, our concern was with the extent to which each meal raised glucose levels above baseline, therefore only the area above baseline was integrated, glucose +iAUC and insulin iAUC), the maximum concentration attained (glucose $C_{\max }$ and insulin $C_{\max }$ ) and change in concentration between 30 and 60 min following commencement of the meal (glucose $\Delta 30-60$ and insulin $\Delta 30-60$ ). In post hoc analysis, indices of basal insulin sensitivity and $\beta$-cell function were calculated using homeostasis model assessment as follows ${ }^{(20)}$ :

$$
\begin{gathered}
\text { HOMA }- \text { IS }=1 /\left(\left(G_{\mathrm{b}} \times I_{\mathrm{b}}\right) / 22 \cdot 5\right), \\
\text { HOMA }-\mathrm{B}=20 \times\left(I_{\mathrm{b}} /\left(G_{\mathrm{b}}-3 \cdot 5\right)\right) .
\end{gathered}
$$

Postprandial insulin sensitivity was expressed by the Matsuda Index, calculated as:

$$
\text { Matsuda }- \text { IS }=1000 /\left(G_{\mathrm{b}} \times I_{\mathrm{b}} \times G_{\text {mean }} \times I_{\text {mean }}\right)^{0.5},
$$

where $G_{\text {mean }}$ and $I_{\text {mean }}$ are the mean postprandial glucose and insulin concentrations ${ }^{(21)}$. Postprandial $\beta$-cell 
function was expressed as the insulinogenic index, calculated as the insulin concentration $30 \mathrm{~min}$ following the start of meal ingestion divided by the accompanying glucose concentration $^{(21)}$.

Differences between the meals were tested using linear mixed models with subject treated as a random effect (with a variance component error structure) and including fixed effects of baseline (for that meal), subject baseline (i.e. the subject's average baseline overall meals), subject weight, visit number and meal. Each PAL meal was compared statistically with the REF. Because the HOMA-IS, HOMA-B, Matsuda Index and Insulinogenic Index had distributions that were not symmetric, non-parametric Mann-Whitney tests were used to compare the PAL meals with the REF for each of these. The analysis was carried out using SAS Software version 9.3 (SAS Institute).

\section{Results}

Of the twenty-four volunteers, twenty-one completed the study. In the blind review, meals where there were protocol deviations (failure to finish the meal in the allotted time) were removed from the per-protocol analysis. After blind review 1, volunteer was removed completely from all analyses, as an obvious outlier in the baseline value for GLP-1 (mean baseline for all subjects $16 \mathrm{pmol} / \mathrm{l}$, excluded subject baseline $997 \mathrm{pmol} / \mathrm{l})$. There were seventeen subjects in the per-protocol analysis set for PAL1 and the same nineteen for both PAL2 and REF. Baseline demographics for the three groups are presented in Table 2 .

\section{Postprandial glucose and insulin responses}

The results for glucose and insulin responses are summarised in Table 3. In post boc analysis, there were no differences in the basal measures $G_{\mathrm{b}}, I_{\mathrm{b}}$, HOMA-IS or HOMA-B before the commencement of each of the three meals. Postprandially, glucose levels with the REF fell between 30 and 60 min to the levels below baseline following the commencement of

Table 2. Baseline demographics and clinical characteristics of the study subjects from each group used in the analysis

(Mean values and standard deviations)

\begin{tabular}{|c|c|c|c|c|c|c|}
\hline & \multicolumn{2}{|c|}{ PAL1 } & \multicolumn{2}{|c|}{ PAL2 } & \multicolumn{2}{|c|}{ REF } \\
\hline & Mean & SD & Mean & SD & Mean & SD \\
\hline$n$ & \multicolumn{2}{|c|}{17} & \multicolumn{2}{|c|}{19} & \multicolumn{2}{|c|}{19} \\
\hline Age (years) & 27.9 & $13 \cdot 22$ & $27 \cdot 5$ & $12 \cdot 68$ & $27 \cdot 5$ & $12 \cdot 68$ \\
\hline Weight (kg) & $74 \cdot 2$ & 7.40 & 74.5 & 7.55 & 74.5 & 7.55 \\
\hline $\operatorname{BMI}\left(\mathrm{kg} / \mathrm{m}^{2}\right)$ & $23 \cdot 4$ & $2 \cdot 67$ & 23.4 & 2.56 & $23 \cdot 4$ & 2.56 \\
\hline Glucose $(\mathrm{mmol} / \mathrm{l})$ & 5.5 & 0.45 & $5 \cdot 3$ & 0.36 & 5.4 & 0.39 \\
\hline Insulin (pmol//) & $59 \cdot 6$ & $30 \cdot 32$ & 44.9 & $20 \cdot 00$ & $56 \cdot 0$ & $35 \cdot 11$ \\
\hline GLP-1 (pmol/l) & 4.7 & $2 \cdot 61$ & $5 \cdot 2$ & $2 \cdot 86$ & $5 \cdot 1$ & 2.42 \\
\hline GIP (pmol/l) & $8 \cdot 6$ & 6.34 & 8.4 & 5.41 & 8.5 & 4.73 \\
\hline PYY (pmol/l/) & $27 \cdot 8$ & 18.06 & $27 \cdot 4$ & $16 \cdot 64$ & $27 \cdot 2$ & $16 \cdot 60$ \\
\hline
\end{tabular}

PAL1, Palaeolithic meal 1; PAL2, Palaeolithic meal 2; REF, reference meal; GLP-1, glucagon-like peptide-1; GIP, glucose-dependent insulinotropic peptide; PYY, peptide $Y Y$. the meal, and then recovered to basal levels over the next hour (Fig. 1(a)). A similar profile was apparent with PAL1, except that glucose levels remained below baseline from 60 to $120 \mathrm{~min}$. With PAL2, glucose levels also fell from 30 to $60 \mathrm{~min}$ but did not fall below baseline and remained at the basal level from 60 to $120 \mathrm{~min}$. Despite these differences, no significant differences were observed in glucose + iAUC $_{120}$ or insulin $\mathrm{iAUC}_{120}$ between the meals (Table 3, Fig. 1(a) and (b)). Glucose $C_{\max }$ did not differ between the meals, but insulin $C_{\max }$ was significantly lower $(P=0 \cdot 040)$ for PAL2 (mean 264.8 (sE 32.42) pmol/l) relative to the REF (mean $339 \cdot 0(\mathrm{se} 31 \cdot 40) \mathrm{pmol} / \mathrm{l})$. There was a smaller decline in glucose levels from 30 to $60 \mathrm{~min}(P=0 \cdot 001)$ for PAL2 (glucose $\Delta 30-60$ mean $-0.89($ se $0 \cdot 14) \mathrm{mmol} / \mathrm{l})$ than the REF (glucose $\Delta 30-60$ mean $-1.48(\operatorname{se} 0 \cdot 14) \mathrm{mmol} / \mathrm{l}$ ), indicating a slower rate of decline in glucose levels with PAL2. Matsuda-IS did not differ between the meals, but the insulinogenic index was significantly lower $(P=0.02)$ for PAL2 (median 4.88 , interquartile range $3.73-6.73$ ) relative to the REF (median 6.33 , interquartile range $4 \cdot 94-7 \cdot 86$ ).

\section{Postprandial gut hormone responses}

$\mathrm{AUC}_{180}$ values for all the gut hormones measured are summarised in Table 4. AUC 180 values for GLP-1 and PYY (Fig. 2(a) and (b)) were found to be dramatically higher for both PAL meals compared with the REF, while $\mathrm{AUC}_{180}$ values for GIP (Fig. 2(c)) were significantly lower for both PAL meals. Additionally, the 'shape' of the GIP response was completely different. The $\mathrm{AUC}_{180}$ for pancreatic polypeptide was significantly higher $(P<0 \cdot 001)$ only for PAL1 with respect to the REF, and leptin was significantly lower for PAL2 $(P=0.031)$. There were no differences between the meals with respect to ghrelin or amylin levels.

\section{Glucose elimination, insulinogenic index and incretin hormones}

Possible explanations for the slower decline in glucose levels with PAL2 were explored in post hoc regression analyses. A slower decline in glucose levels $(\Delta 30-60$ more negative) was predicted by a lower insulinogenic index $(\beta=0 \cdot 106$, $P=0.001)$ and, in a separate analysis, by $\operatorname{PAL} 2(\beta=-0.492$, $P=0.016$ ). When the insulinogenic index was added to the model, PAL2 ceased to be a significant predictor ( $\beta=-0 \cdot 317, P=0 \cdot 11)$ in accord with a lower insulinogenic index contributing the slower decline in glucose levels with PAL2. The GLP-1 response (iAUC between 0 and $30 \mathrm{~min}$ ) did not predict the insulinogenic index $(\beta=-0.002, P=0.28)$, whereas the equivalent measure for GIP was predictive at borderline significance $\left(\beta=2.72 \times 10^{-4}, P=0.074\right)$. A lower insulinogenic index was predicted by PAL2 $(\beta=-1.949$, $P=0.02)$. When the GIP response was added to the model, PAL2 ceased to be a significant predictor of the insulinogenic index $(\beta=-1 \cdot 790, P=0 \cdot 14)$, in accord with the lower GIP response contributing the lower insulinogenic index with PAL2. However, in the stepwise multivariable analysis, with the entry of all potential predictors of the insulinogenic 
Table 3. Postprandial glucose and insulin data for twenty-one subjects after consumption of two Palaeolithically inspired meals (PAL1 and PAL2) compared with a reference meal (REF)

(Mean values with their standard errors; medians and interquartile ranges (IQR))

\begin{tabular}{|c|c|c|c|c|c|c|c|c|}
\hline & \multicolumn{2}{|c|}{ REF } & \multicolumn{2}{|c|}{ PAL1 } & \multirow[b]{2}{*}{$P^{\star} v \cdot \mathrm{REF}$} & \multicolumn{2}{|c|}{ PAL2 } & \multirow[b]{2}{*}{$P^{\star} v$. REF } \\
\hline & Mean & SE & Mean & SE & & Mean & SE & \\
\hline$G_{\mathrm{b}}(\mathrm{mmol} / \mathrm{l})$ & & & & & 0.3 & & & 0.7 \\
\hline Median & \multirow{2}{*}{\multicolumn{2}{|c|}{$\begin{array}{c}5 \cdot 3 \\
5 \cdot 2-5 \cdot 7\end{array}$}} & \multirow{2}{*}{\multicolumn{2}{|c|}{$\begin{array}{c}5 \cdot 4 \\
5 \cdot 0-5 \cdot 6\end{array}$}} & \multirow{2}{*}{\multicolumn{4}{|c|}{$\begin{array}{c}5 \cdot 2 \\
5 \cdot 1-5 \cdot 8\end{array}$}} \\
\hline IQR & & & & & & & & \\
\hline Glucose $+\mathrm{iAUC}_{120}(\mathrm{~min} \times \mathrm{mmol} / \mathrm{l})$ & $35 \cdot 1$ & 6.06 & 24.8 & $6 \cdot 74$ & 0.224 & $46 \cdot 4$ & $6 \cdot 35$ & 0.169 \\
\hline Glucose $C_{\max }(\mathrm{mmol} / \mathrm{l})$ & 6.45 & 0.108 & $6 \cdot 22$ & 0.118 & $0 \cdot 101$ & 6.41 & 0.112 & 0.764 \\
\hline Glucose $\Delta 30-60(\mathrm{mmol} / \mathrm{l})$ & -1.48 & -0.140 & $-1 \cdot 16$ & -0.153 & 0.062 & -0.89 & 0.145 & $<0.001$ \\
\hline$I_{\mathrm{b}}(\mathrm{pmol} / \mathrm{l})$ & \multirow{3}{*}{\multicolumn{2}{|c|}{$\begin{array}{c}49 \cdot 2 \\
29 \cdot 8-71 \cdot 6\end{array}$}} & & & 0.7 & & & 0.3 \\
\hline Median & & & \multirow{2}{*}{\multicolumn{2}{|c|}{$\begin{array}{c}48 \cdot 3 \\
39 \cdot 0-72 \cdot 4\end{array}$}} & \multirow{2}{*}{\multicolumn{4}{|c|}{$\begin{array}{c}38.5 \\
28.0-51.9\end{array}$}} \\
\hline IQR & & & & & & & & \\
\hline Insulin iAUC ${ }_{120}(\mathrm{~min} \times \mathrm{pmol} / \mathrm{l})$ & 14278 & $2030 \cdot 1$ & 16843 & $2155 \cdot 0$ & 0.236 & 13303 & $2087 \cdot 2$ & 0.643 \\
\hline Insulin $C_{\max }(\mathrm{pmol} / \mathrm{l})$ & 339.0 & 31.40 & $310 \cdot 0$ & 33.6 & 0.415 & 264.8 & 32.42 & 0.040 \\
\hline Insulin $\Delta 30-60(\mathrm{pmol} / \mathrm{l})$ & $-184 \cdot 1$ & $28 \cdot 24$ & $-58 \cdot 3$ & $32 \cdot 34$ & 0.007 & -77.5 & 29.83 & 0.014 \\
\hline HOMA-IS & & & & & 0.57 & & & 0.33 \\
\hline Median & \multirow{2}{*}{\multicolumn{2}{|c|}{$\begin{array}{c}0.60 \\
0.38-1.05\end{array}$}} & \multirow{2}{*}{\multicolumn{2}{|c|}{$\begin{array}{c}0.64 \\
0.35-0.75\end{array}$}} & \multicolumn{4}{|c|}{0.77} \\
\hline IQR & & & & & & 0.5 & & \\
\hline HOMA-B & & & & \multicolumn{3}{|l|}{0.64} & 0.60 \\
\hline Median & \multirow{2}{*}{\multicolumn{2}{|c|}{$\begin{array}{c}80 \cdot 8 \\
50 \cdot 8-91.7\end{array}$}} & \multirow{2}{*}{\multicolumn{2}{|c|}{$\begin{array}{c}77 \cdot 3 \\
60 \cdot 8-92 \cdot 6\end{array}$}} & \multirow{2}{*}{\multicolumn{4}{|c|}{63.1}} \\
\hline IQR & & & & & \multicolumn{3}{|c|}{$54 \cdot 4-101 \cdot 0$} & \\
\hline Matsuda-IS & & & & & 0.55 & & & 0.47 \\
\hline Median & \multicolumn{2}{|c|}{$\begin{array}{c}173 \\
84-199\end{array}$} & \multicolumn{2}{|c|}{147} & \multicolumn{4}{|c|}{163} \\
\hline IQR & \multicolumn{2}{|c|}{$84-199$} & \multicolumn{2}{|c|}{$99-183$} & \multicolumn{4}{|c|}{$136-224$} \\
\hline Insulinogenic index & \multirow{2}{*}{\multicolumn{2}{|c|}{$6 \cdot 33$}} & \multirow{2}{*}{\multicolumn{2}{|c|}{6.50}} & 1.0 & & & 0.03 \\
\hline Median & & & & & \multicolumn{4}{|c|}{4.88} \\
\hline IQR & \multicolumn{2}{|c|}{$4.94-7.86$} & 4.6 & .49 & & $3 \cdot 7$ & 73 & \\
\hline
\end{tabular}

$G_{\mathrm{b}}$, glucose basal; +iAUC, positive incremental AUC; $C_{\max }$, maximum concentration; $l_{\mathrm{b}}$, insulin basal; HOMA-IS, homeostasis model assessment: basal insulin sensitivity; HOMA-B, homeostasis model assessment: basal $\beta$-cell function; Matsuda Index-IS, Matsuda Index-insulin sensitivity.

${ }^{*} P$ values for all tests expect HOMA-IS, HOMA-B, Matsuda Index and Insulinogenic Index were obtained from ANCOVA models with a baseline covariate and $95 \%$ CI. The remaining indices were based on Mann-Whitney non-parametric tests.

index (BMI, meal type and glucose, GIP, GLP-1 and PYY incremental responses during the first $30 \mathrm{~min}$ of the meal), PAL2 was the strongest independent predictor of a low insulinogenic index $(\beta=-2 \cdot 349, \quad P=0.002)$, with initial glucose response as the only other potential independent predictor, albeit at borderline significance $(\beta=0 \cdot 013, P=0 \cdot 05)$.

\section{Postprandial satiety electronic visual analogue scale scores}

The mean response levels over $175 \mathrm{~min}$ for the satiety questions were all statistically significantly different for both PAL1 and PAL2 with respect to the REF (see Table 4). The response level for all the three satiety questions was consistent throughout the time of the study for both PAL meals with respect to the REF, and was still higher for both meals at $175 \mathrm{~min}$ (Fig. 3). Percentage changes from the REF for 'How hungry are you?' were $44.67 \%$ for PAL1 and $38.44 \%$ for PAL2, for 'How full are you?' were $-57 \cdot 28 \%$ for PAL1, and $-50.59 \%$ for PAL2 and for 'How strong is your desire to eat a meal?', $46.94 \%$ for PAL1 and 33.43\% for PAL2. Liking scores for PAL1 and PAL2 were $25 \cdot 1$ and $25 \cdot 5$, respectively, which were significantly lower $(P<0 \cdot 0001)$ than those for the REF $(60 \cdot 2)$.

\section{Discussion}

Acute consumption of plant-rich mixed meals gave a significant increase in the release of appetite-related gut hormones
GLP-1 and PYY, and improved satiety, but made little impact on glycaemic control. The incretin hormone GIP was dramatically lower and showed a very different response curve for both PAL1 and PAL2 in comparison with the REF.
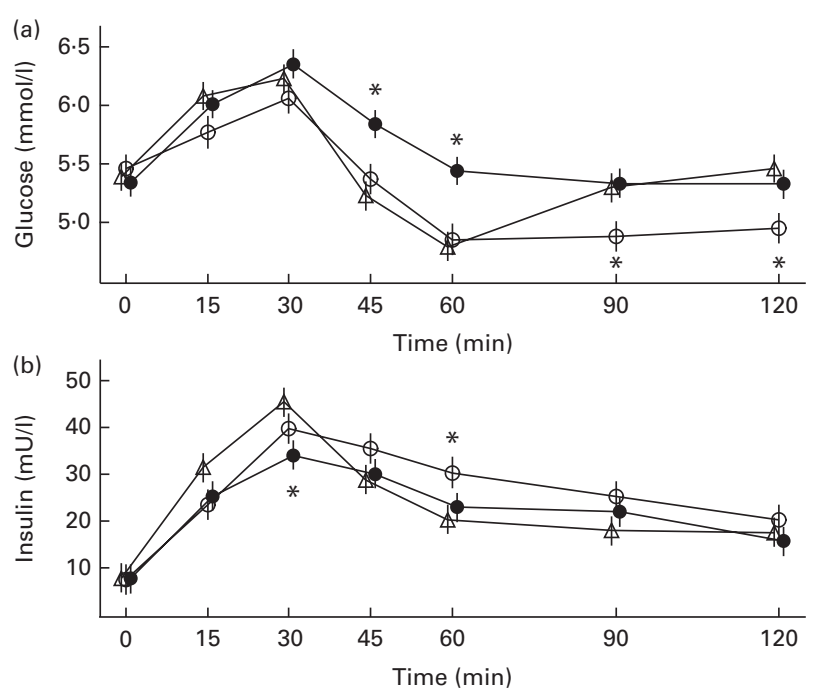

Fig. 1. Plasma glucose (a) and insulin (b) concentrations for twenty-one subjects after consumption of Palaeolithically inspired PAL1 $(\bigcirc)$ and PAL2 (๑) and a reference meal $(\Delta)$. Values are means, with standard errors represented by vertical bars. * Mean value was significantly different from that of the reference meal $(P<0.05)$. A Bonferroni adjustment was used to preserve the 0.05 error rate within each time point. To convert insulin in $\mathrm{mU} / \mathrm{l}$ to $\mathrm{pmol} / \mathrm{l}$, multiply by 6.945 . 
Table 4. Postprandial gut hormone and appetite data for twenty-one subjects after consumption of two Palaeolithically inspired meals (PAL1 and PAL2) compared with a reference meal (REF)

(Mean values with their standard errors)

\begin{tabular}{|c|c|c|c|c|c|c|c|c|}
\hline & \multicolumn{2}{|c|}{ REF } & \multicolumn{2}{|c|}{ PAL1 } & \multirow[b]{2}{*}{$P^{\star} v$. REF } & \multicolumn{2}{|c|}{ PAL2 } & \multirow[b]{2}{*}{$P^{\star} v . \mathrm{REF}$} \\
\hline & Mean & SE & Mean & SE & & Mean & SE & \\
\hline PYY AUC $180(\min \times p m o l / l)$ & 5027 & 121.9 & 5493 & $127 \cdot 0$ & 0.001 & 5329 & 121.6 & 0.011 \\
\hline GLP-1 AUC $_{180}(\min \times \mathrm{pmol} / \mathrm{l})$ & 980 & $63 \cdot 3$ & 1494 & $66 \cdot 1$ & $<0.001$ & 1180 & 64.4 & 0.003 \\
\hline $\mathrm{GIP} \mathrm{AUC}_{180}(\mathrm{~min} \times \mathrm{pmol} / \mathrm{l})$ & 7576 & 352.7 & 4926 & 377.5 & $<0.001$ & 3814 & $350 \cdot 8$ & $<0.001$ \\
\hline \multicolumn{9}{|l|}{ Mean satiety score over $175 \mathrm{~min}$} \\
\hline Hungry & $55 \cdot 4$ & $3 \cdot 64$ & $30 \cdot 6$ & $3 \cdot 80$ & $<0.001$ & $34 \cdot 1$ & $3 \cdot 64$ & $<0.001$ \\
\hline Full & $38 \cdot 2$ & 3.77 & $60 \cdot 0$ & 3.87 & $<0.001$ & 57.5 & 3.72 & $<0.001$ \\
\hline Desire to eat a meal & $57 \cdot 6$ & 3.94 & $30 \cdot 5$ & $4 \cdot 11$ & $<0.001$ & $38 \cdot 1$ & 3.96 & $<0.001$ \\
\hline \multicolumn{9}{|l|}{ Satiety quotient (per MJ), $t=175$} \\
\hline Hungry & 4.50 & $2 \cdot 63$ & 11.63 & $2 \cdot 73$ & 0.014 & $17 \cdot 45$ & $2 \cdot 67$ & $<0.001$ \\
\hline Full & $7 \cdot 67$ & 2.79 & 11.83 & $2 \cdot 87$ & 0.139 & $16 \cdot 62$ & $2 \cdot 82$ & 0.001 \\
\hline Desire to eat a meal & 5.03 & $2 \cdot 92$ & 11.73 & 3.03 & 0.044 & 14.99 & 2.97 & 0.002 \\
\hline Ghrelin $\mathrm{AUC}_{180}(\mathrm{~min} \times \mathrm{pmol} / \mathrm{l})$ & 1377 & $97 \cdot 6$ & 1446 & $105 \cdot 6$ & 0.609 & 1505 & $96 \cdot 9$ & 0.300 \\
\hline Leptin $\mathrm{AUC}_{180}(\mathrm{~min} \times \mathrm{pmol} / \mathrm{l})$ & 38990 & 1242 & 38863 & 1286 & 0.909 & 36695 & 1236 & 0.031 \\
\hline $\mathrm{PP} \mathrm{AUC}_{180}(\mathrm{~min} \times \mathrm{pmol} / \mathrm{l})$ & 10416 & 1078 & 16568 & 1110 & $<0.001$ & 12353 & 1080 & 0.060 \\
\hline Amylin $\mathrm{AUC}_{180}(\mathrm{~min} \times \mathrm{pmol} / \mathrm{l})$ & 4537 & $391 \cdot 2$ & 4761 & $408 \cdot 8$ & 0.578 & 4028 & 391.4 & $0 \cdot 186$ \\
\hline
\end{tabular}

\section{Glycaemic response}

The primary hypothesis that glycaemic control would be improved with plant-rich meals was not supported by the study findings: no difference between the meals was observed in the glucose $+\mathrm{iAUC}_{120}$; neither was there any difference in insulin $\mathrm{iAUC}_{120}$. However, it should be emphasised that these were acute studies in healthy volunteers with normal glycaemic control. Subtle meal-related differences were observed when the concentration $v$. time curves were reviewed. Notably, PAL2 was associated with a slower decline in glucose concentrations from 30 to $60 \mathrm{~min}$ and the glucose level did not drop below the baseline level. In contrast, both REF and PAL1 were associated with a more rapid decline and, by $60 \mathrm{~min}$, glucose was fallen below the baseline level, albeit to recover during the REF but not during PAL1. This pattern has been linked to a rise in counter regulatory hormones and a deterioration in second-meal glycaemic control ${ }^{(22)}$

The greater control of glucose homeostasis observed with PAL2 could be explained by a lower insulinogenic index and less of an increase in GIP response relative to the REF (although in full multivariable analysis, the effect of GIP was no longer apparent), and might be explained by the positive effect of GIP on $\beta$-cell function, as has been reported previously $^{(23,24)}$.

A reduction in the insulinogenic index is, conventionally, taken to indicate the impairment of $\beta$-cell function; however, the return to basal glucose levels by $60 \mathrm{~min}$ following the commencement of PAL2 implies entirely normal glucose tolerance. Moreover, glucose concentrations with PAL2 did not show the exaggerated decline that was apparent with the REF and PAL1, which suggests that the initial insulin response to PAL2 was appropriate and that the responses to the REF and PAL1 were exaggerated. GLP-1 is understood to have a stronger incretin effect than $\mathrm{GIP}^{(25)}$, and a clear dose-response relationship between GLP-1 and $\beta$-cell response has been reported, although this has only been demonstrated in exogenous infusion studies ${ }^{(26)}$. PAL1 was associated with the highest GLP-1 response, which might have been expected to contribute to the somewhat higher, albeit non-significant, insulinogenic index and rate of decline in glucose levels, compared with PAL2 (despite PAL1 and PAL2 having considerably lower GIP responses than the REF). However, surprisingly, no relationship was apparent between the GLP-1 and meal insulin responses.

\section{Gastrointestinal hormone responses}

Secretion of PYY and GLP-1 from neuroendocrine L-cells in the intestine is stimulated by specific nutrients (dietary fat, protein and SCFA) acting on nutrient-sensing G proteincoupled receptors ${ }^{(27)}$. This process is complex and not fully understood and involves an array of $G$ protein-coupled receptors, as well as non-receptor-mediated effects, stretch receptors and sensory influences. The interactions between signals generated by food, digestion, enzyme secretion and secretions in the stomach, are all considered factors thought to link the nutrient density and digestibility of a meal to facilitate control of gastrointestinal transit and appetite in order to maximise the absorption of valuable nutrients. The initial GLP-1 levels observed here suggest an early signalling of the presence of glucose in the stomach, as proposed by Schirra et $a{ }^{(28)}$, and then a second response for both PAL meals suggesting the presence of glucose still in the lumen of the lower gut, possibly due to reduced bioavailability, before reaching the lower part of the duodenum. By contrast, the REF shows an initial surge, but no secondary response, suggesting that the majority of glucose has been removed from the gut by the time the meal reaches this area. This low response is probably due, at least in part, to the comparatively small meal size and carbohydrate load ${ }^{(28)}$, although it is interesting to note that PAL2 is similar for both energy 

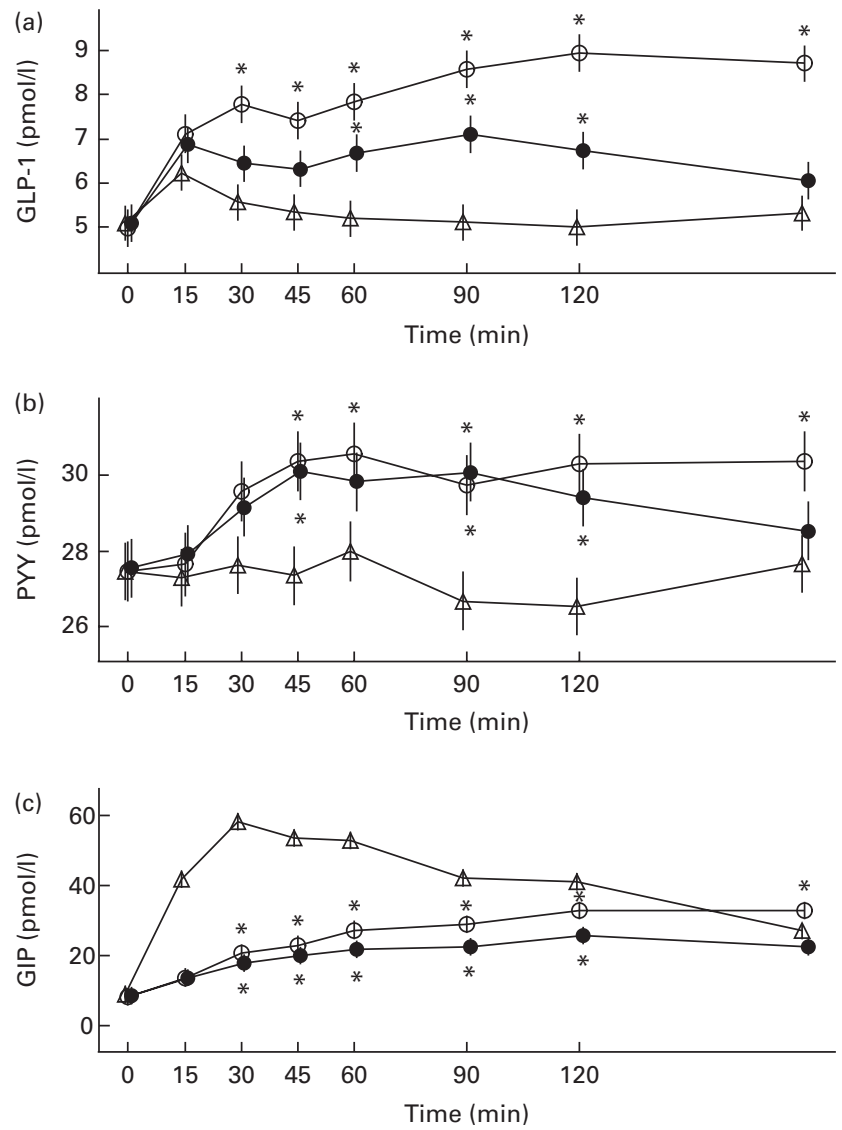

Fig. 2. Postprandial plasma glucagon-like peptide 1 (GLP-1) (a) peptide $Y Y$ (PYY) (b) and glucose-dependent insulinotropic peptide (GIP) (c) responses after consumption of Palaeolithically inspired PAL1 $(O)$ and PAL2 $(\bullet)$, and a reference meal (REF). Values are means, with standard errors represented by vertical bars. * Mean value was significantly different from that of the reference meal $(P<0.05)$. A Bonferroni adjustment was used to preserve the 0.05 error rate within each time point. The mean AUC for $180 \mathrm{~min}$ for GLP-1 were 1494 (SE 66.1) $\mathrm{min} \times \mathrm{pmol} / \mathrm{l}$ for PAL1, 1180 (SE 64.4) $\mathrm{min} \times \mathrm{pmol} / \mathrm{l}$ for PAL2 and 980 (SE 63.3) $\mathrm{min} \times \mathrm{pmol} / \mathrm{l}$ for the REF (PAL1 v. REF $P<0.001$; PAL2 $v$. REF $P=0.003$ )

and carbohydrate load and still elicits a secondary GLP-1 response and one that is overall greater than the REF. This suggests that GLP-1 induction in mixed meals is controlled by more than the size of glucose load, as has recently been suggested $^{(29)}$. GLP-1 response is informed by protein and fat load as well as carbohydrate ${ }^{(30-32)}$, and this is confirmed by the higher PAL1 response over the other meals. However, the similar levels of both fat and protein across PAL2 and REF make this an unlikely explanation for the differences between these other two meals. While the greater volume and mass of the PAL meals may have played a role in EVAS responses generated here, this alone seems unlikely to be responsible for the concomitant rise in satiety hormones. Studies on PYY and gastric volume alone have shown no link between volume and response ${ }^{(33)}$, while other studies have also shown that the PYY response is linked directly to nutrient content ${ }^{(34)}$. Despite the reported link between the high PYY response and protein levels, the data for the low- and high-protein PAL meals follow the same response up until the last time point.
The dramatically reduced GIP levels observed for both PAL meals are particularly intriguing, and may, in part, be explained by the available carbohydrate constituting a higher level of fructose in the PAL meals ${ }^{(35)}$. However, previous work on mixed meals with free fructose suggest that the presence of both fructose and glucose would have caused only a slightly lower peak in the GIP response ${ }^{(36)}$, rather than the very delayed response that is observed here. GIP has also been shown to be induced by lipid as well as glucose, although studies on protein vary ${ }^{(30)}$. However, again, while total fat was higher in PAL1, this cannot account for the striking difference observed between PAL2 and REF, which had similar fat levels.

The overall data suggest that some aspect of the PAL meals renders glucose less accessible, which is the mechanism by which GIP is induced ${ }^{(37)}$; however, this can only be hypothesised as the glucose measurements cannot distinguish here between glucose absorption and uptake. While delayed gastric emptying alone could explain the delayed GIP response for the PAL meals, the later raised GLP-1 response suggests the delivery of unabsorbed glucose to the lower duodenum where there is higher $\mathrm{L}$ cell and lower $\mathrm{K}$ cell abundance.
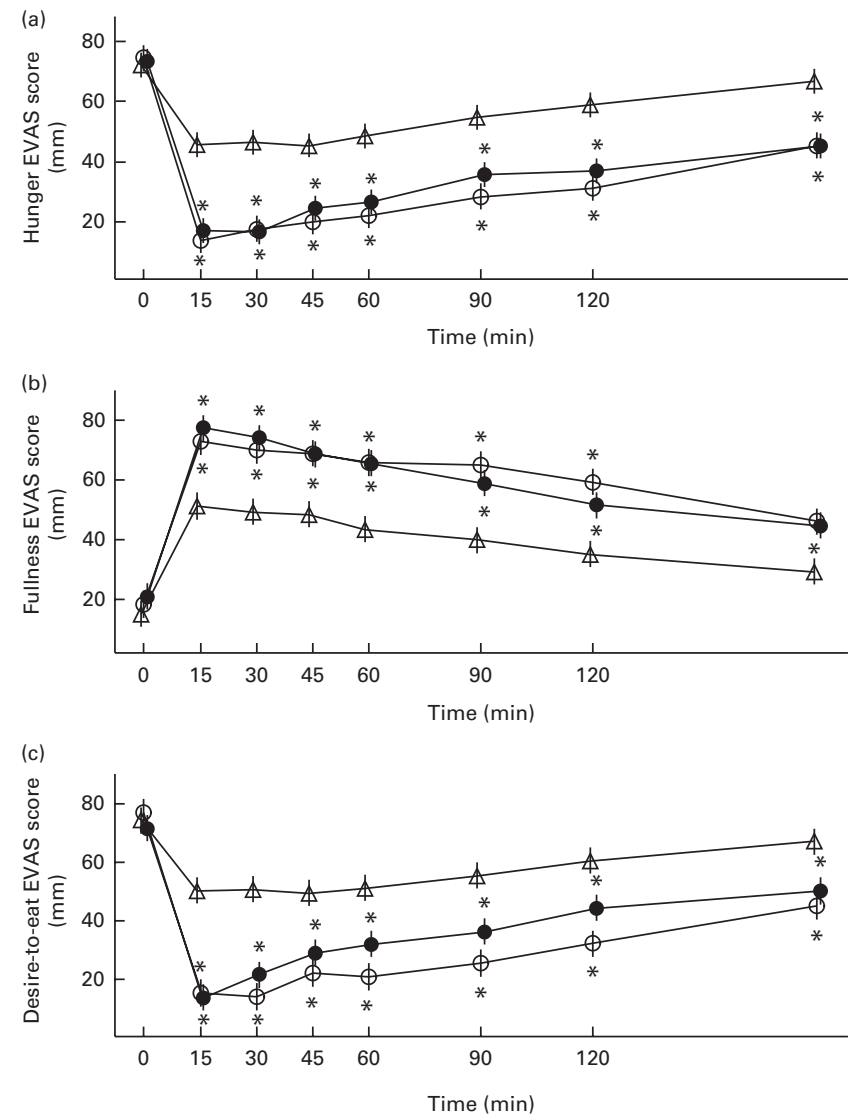

Fig. 3. Electronic visual analogue scale (EVAS) response scores over time after consumption of Palaeolithically inspired PAL1 $(\bigcirc)$ and PAL2 $(\bullet)$ and a reference meal $(\Delta)$. (a) Response to question 'How hungry are you?', (b) response to question 'How full are you?' and (c) response to question 'How strong is your desire to eat a meal?'. Values are means, with standard errors represented by vertical bars. * Mean value was significantly different from that of the reference meal $(P<0.05)$. A Bonferroni adjustment was used to preserve the 0.05 error rate within each time point. 
The authors speculate that a possible explanation for this could be flavonoids in the PAL meals, inhibiting glucose absorption in the jejunum ${ }^{(38,39)}$, as delayed gastric emptying alone would be expected to give a GLP-1 response that was even further delayed than that observed here for GIP. However, it seems unlikely that delayed response alone can account for the magnitude of the differences in both GLP-1 and PYY responses observed between PAL2 and REF. This hypothesis would allow for the high GLP-1 level, in that glucose would be transported to the lower part of the duodenum unabsorbed where the presence of glucose in the lumen would induce the higher levels of GLP-1 observed here. This would also be supported by the higher levels of phenolic compounds extracted from PAL1 and PAL2 when compared with the REF $(57 \cdot 2,86 \cdot 1$ and $4.47 \mathrm{mg} \mathrm{GAE}$, respectively). As the extraction process for this did not use lipophilic extraction solvents and acid hydrolysis, which remove cell wall-bound hydroxycinnamic acids, and used Amberchrom column chromatography, these phenolics would be expected to be largely flavonoids.

Recent studies have shown a link between high-energy density foods and long-term PYY levels ${ }^{(40)}$, but none (to our knowledge) have shown an overall long-term pattern of response for GLP-1 and GIP levels. The higher volume of the meals from ingredients as opposed to added water or other artificial means of increasing volume would suggest that it is volume coupled with nutrient content, which is then released as the food passes through the gut, that is responsible for the hormone responses observed here. It is tempting to speculate that the rate of gastric flow may play a role in delayed delivery, as both PYY and GLP-1 have been implicated in the ileal brake; however, this needs confirmation and is an area we plan to pursue in further studies.

Of the remaining hormones measured in the present study (pancreatic polypeptide, amylin, ghrelin and leptin), while pancreatic polypeptide showed a increased response for both PAL meals, none of the other hormones showed any consistent significant differences for the AUC between the three meals (see Table 4).

There is no known single lifestyle intervention that can ameliorate obesity and T2D risk factors. However, bariatric surgery has been shown to result in lowering of GIP with a concomitant rise in PYY and in some cases also GLP-1, as discussed above, and these factors are thought to play a role in insulin sensitivity and appetite regulation ${ }^{(41,42)}$. A similar reduction in GIP and rise in PYY, along with a related improved insulin sensitivity, has also been found as a result of lifestyle change studies ${ }^{(43,44)}$.

Independently of their role in insulin and glucose control, there are also emerging data showing that both GIP and GLP-1 can play a role in other negative physiological responses to diet, such as fatty liver and obesity ${ }^{(45)}$. The reduced GIP response, in particular, would justify further study in the light of data on knockout mice, which suggest that this hormone has a role to play in how the body metabolises and stores fat ${ }^{(46)}$. However, further studies on the longerterm effects of this would be needed to link GIP response to longer-term weight loss in human subjects.

\section{Appetite response}

The satiety scores for the three test meals were significantly improved across all the three questions for both PAL meals (Table 4; Fig. 3), and yet, despite the higher energy and protein content of PAL1, there was no significant difference between these two meals until the final time point recorded. In fact, satiety quotient per unit energy ${ }^{(47)}$ for all the three EVAS questions at $175 \mathrm{~min}$ shows that PAL2 gives the greatest level of satiety per kJ. Both PAL meals also showed higher levels of PYY, which has been shown to play a key role in appetite and energy intake reduction ${ }^{(48)}$, although levels for both PAL meals are very similar, contradictory to reports that this hormone is energetically governed ${ }^{(49)}$. GLP-1 affects the ileal brake, resulting in slower gastric emptying ${ }^{(28,50)}$, and this could also have been a factor in the higher satiety ratings recorded for both PAL meals. A major similarity of the two PAL meals is the overall lower energy density caused by the minimal processing and cooking of the plant matter, causing the PAL meals to have a higher integral water content, although total dry weights of the matched PAL2 and REF were almost identical (HFJ Bligh and KJ Hunter, unpublished results). While the high volume and weight of the two PAL meals are likely to be a contributing factor to the initial EVAS scores observed here, it seems unlikely that this alone can account for the high and sustained level of PYY and GLP-1, which are observed to map the EVAS scores. However, this does suggest that the low energy density of the Palaeolithic-type meals from the high plant content is a contributory factor in the recorded satiety in the present and other studies, rather than just high protein, as has been suggested previously ${ }^{(8,9,51)}$.

It is interesting to note that GLP-1 agonists are currently being explored as treatments for both diabetes and obesity, and the present study gives some indication that the levels of both GLP-1 and PYY could also be controlled nutritionally. The higher fibre content of the PAL meals, combined with the fact that this fibre would still be complex with the plant cell structure, would provide another contributor to the satiety and appetite scores. However, it is difficult to see how this alone can account for the incretin responses observed here, as the presence of fibre in some studies appears to suppress GLP-1 ${ }^{(31,32)}$ and increased fibre alone does not necessarily lead to enhanced satiety ${ }^{(52)}$. It should also be noted that Jönsson et al. $^{(9)}$ appeared to also discount fibre as the sole explanation for their satiety data. There has also been some suggestion that phenolic content can also play a role in appetite response, and this may also have been a factor given the high phenolic load of the PAL meals (Table 1$)^{(53)}$. By contrast, many modern processed foods are not only energy dense, but rapidly and easily digested, and thus do not maintain satiation and satiety for prolonged periods ${ }^{(54)}$.

\section{Critical evaluation of the study}

The EVAS score data were not the primary objective of the present study, and, as such, no ad libitum meal was undertaken. Further studies are currently in progress, and these will include ad libitum meals as part of the further 
investigation into both the satiety and anorectic hormone responses observed here.

The lack of palatability may have played a role in the EVAS scores recorded; however, this may well have been exacerbated by the time of day the meals were consumed, which was necessitated by the need for an overnight fast before consumption. While palatability recorded in the actual study was low, earlier tasting sessions did not raise this as an issue and while palatability probably affected early scores, it seems unlikely that this would have been sustained throughout the period studied or affected the hormone responses observed here.

There was no attempt to tailor the energy content of the meal to the BMI of the subjects, which may have played some role in individual responses. However, due to the complexity of ingredients of the PAL meals and the need to prepare these in advance to reduce batch variation of raw materials, it was not possible to energy match these to the energy requirements of the participants.

\section{Overall conclusion}

A preliminary acute-effects study is consistent with the view that rationally designed Palaeolithic-type meals based on modern foods show potential for delivering benefits in the reduced risk of obesity and even T2D. The findings presented here suggest that this may be mediated through the actions of PYY and GLP-1. Relevant features in meal design, which may be responsible for these effects, include low energy density, high fibre and high polyphenol content. Longerterm studies are needed to confirm this and elucidate the mechanisms of action.

\section{Acknowledgements}

The authors thank Sonia Pombo and colleagues at Leatherhead for conducting the study, Joan Lane for guidance on protocols and ethics, and Professors M. Thomas and M. Richards for helpful discussion. The authors also thank Professor Peter Wilde for critical reviewing of the manuscript

The present study was fully funded by Unilever.

The authors' responsibilities are as follows: J. C., M. J. B., H. F. J. B. and K. J. H. were involved in formulating the original research question; H. F. J. B., K. J. H., M. J. B., P. M., J. C. and T. P. J. M. worked on the design of the study; T. P. J. M. and H. F. J. B. were involved in the practical aspects of the study including meal design and preparation; H. F. J. B., K. J. H., D. H. and D. C. S. T. performed the venous glucose and hormone analysis; P. M. performed the statistical analysis and created the graphs; H. F. J. B., K. J. H., G. F., I. F. G., M. J. B. and K. M. were involved in the interpretation of the study; I. F. G. and G. F. suggested and performed the insulin modelling; H. F. J. B., K. J. H., G. F., I. F. G., J. C. M. J. B. and P. M. were involved in the drafting and reviewing of the manuscript. All authors read and approved the final manuscript.

All authors with the exception of G. F. and I. F. G. are employed by Unilever. G. F. is a consultant for Unilever.

\section{References}

1. Larsson SC \& Alicja Wolk A (2006) Epidemiology of obesity and diabetes: prevalence and trends. In Contemporary Diabetes: Obesity and Diabetes, pp. 15-36 [CS Mantzoros, editor]. Totowa, NJ: Humana Press.

2. Voegtlin WL (1975) The Stone Age Diet: Based on In-Depth Studies of Human Ecology and the Diet of Man. New York: Vantage Press.

3. Boyd Eaton S \& Konner M (1985) Palaeolithic nutrition: a consideration of its nature and current implications. New Eng J Med 312, 283-289.

4. Frassetto LA, Schloetter M, Mietus-Synder M, et al. (2009) Metabolic and physiologic improvements from consuming a paleolithic, hunter-gatherer type diet. Eur J Clin Nutr 63, 947-955.

5. Boers I, Muskiet FA, Berkelaar E, et al. (2014) Favourable effects of consuming a Palaeolithic-type diet on characteristics of the metabolic syndrome: a randomized controlled pilot-study. Lip Health Dis 13, 160-172.

6. Lindeberg S, Jönsson T, Granfeldt Y, et al. (2007) Palaeolithic diet improves glucose tolerance more than a Mediterraneanlike diet in individuals with ischaemic heart disease. Diabetologia 50, 795-1807.

7. Ryberg M, Sandberg S, Mellberg C, et al. (2013) A Palaeolithic-type diet causes strong tissue-specific effects on ectopic fat deposition in obese postmenopausal women. $J$ Int Med 2013, 67-76.

8. Mellberg C, Sandberg S, Ryberg M, et al. (2014) Long-term effects of a Palaeolithic-type diet in obese postmenopausal women: a 2-year randomized trial. Eur J Clin Nutr $\mathbf{6 8}$, $350-357$.

9. Jönsson T, Granfeldt Y, Erlanson-Albertsson C, et al. (2010) A paleolithic diet is more satiating per calorie than a Mediterranean-like diet in individuals with ischemic heart disease. Nutr Metab 7, 85-98.

10. World Health Organisation (1995) Preparation and Use of Food-based Dietary Guidelines. Joint WHO/FAO Expert Consultation, WHO Technical Report Series no. 880. Geneva: WHO.

11. Konner M \& Boyd-Eaton S (2010) Paleolithic nutrition: twenty-five years later. Nutr Clin Prac 25, 594-602.

12. Wang SY, Wei Z \& Galletta GJ (2002) Cultural system affects fruit quality and antioxidant capacity in strawberries. J Agric Food Chem 50, 6534-6542.

13. Tanksley SD \& McCouch SR (1997) Seed banks and molecular maps: unlocking genetic potential from the wild. Science 277, 1063-1066.

14. Anderson RA, Broadhurst CL, Polansky MM, et al. (2004) Isolation and characterization of polyphenol type-A polymers from cinnamon with insulin-like biological activity. J Agric Food Chem 52, 65-70.

15. Inocencio C, Rivera D, Alcaraz F, et al. (2000) Flavonoid content of commercial capers (Capparis spinosa, C. sicula and C. orientalis) produced in Mediterranean countries. Eur Food Res Tech 212, 70-74.

16. Velioglu YS, Mazza G, Gao L, et al. (1998) Antioxidant activity and total phenolics in selected fruits, vegetables, and grain products. J Agric Food Chem 46, 4113-4117.

17. Flint A, Raben A, Blundell JE, et al. (2000) Reproducibility, power and validity of visual analogue scares in assessment of appetite sensations in single test meal studies. Int $J$ Obes 24, 38-48.

18. Stubbs RJ, Hughes DA, Johnstone AM, et al. (2000) The use of visual analogue scales to assess motivation to eat in human subjects: a review of their reliability and validity 
with an evaluation of new hand-held computerized systems for temporal tracking of appetite ratings. Br J Nutr $\mathbf{8 4}$, $405-415$

19. Stratton RJ, Stubbs RJ, Hughes D, et al. (1998) Comparison of the traditional paper visual analogue scale questionnaire with an Apple Newton electronic appetite rating system (EARS) in free living subjects feeding ad libitum. Eur J Clin Nutr 52, 737-741.

20. Matthews DR, Hosker JP, Rudenski AS, et al. (1985) Homeostasis model assessment: insulin resistance and $\beta$-cell function from fasting plasma glucose and insulin concentrations in man. Diabetologia 28, 412-419.

21. Maki KC, Kelley KM, Lawless AL, et al. (2011) Validation of insulin sensitivity and secretion indices derived from the liquid meal tolerance test. Diabetes Tech Ther 13, 661-666.

22. Ludwig DS (2002) The glycemic index: physiological mechanisms relating to obesity, diabetes, and cardiovascular disease. JAMA 287, 2414-2423.

23. Harada N, Hamasaki A, Yamane S, et al. (2011) Plasma gastric inhibitory polypeptide and glucagon-like peptide-1 levels after glucose loading are associated with different factors in Japanese subjects. J Diabetes Investig 2, 193-199.

24. Yamane Y, Harada N, Hamasaki A, et al. (2012) Effects of glucose and meal ingestion on incretin in Japanese subjects with normal glucose tolerance. J Diabetes Investig 3, 80-85.

25. Kreymann B, Williams G, Ghatei MA, et al. (1987) Glucagonlike peptide-1 7-36: a physiological incretin in man. Lancet ii, $1300-1304$

26. Kjems LL, Holst JJ, Vølund A, et al. (2003) The influence of GLP-1 on glucose-stimulated insulin secretion: effects on $\beta$-cell sensitivity in type 2 and nondiabetic subjects. Diabetes 52, 380-386.

27. Gribble FM (2012) The gut endocrine system as a coordinator of postprandial nutrient homoeostasis. Proc Nutr Soc 71, 456-462.

28. Schirra J, Katschinski M, Weidmann C, et al. (1996) Gastric emptying and release of incretin hormones after glucose ingestion in humans. J Clin Invest 97, 92-103.

29. Rijkelijkhuizen JM, McQuarrie K, Girman CJ, et al. (2010) Effects of meal size and composition on incretin, $\alpha$-cell and $\beta$-cell responses. Metabolism 59, 502-511.

30. Elliott RM, Morgan LM, Tredger JA, et al. (1993) Glucagon-like peptide-1 (7-36)amide and glucose-dependent insulinotropic polypeptide secretion in response to nutrient ingestion in man: acute post-prandial and 24-h secretion patterns. J Endocrinol 138, 159-166.

31. Karhunen LJ, Juvonen KR, Huotari A, et al. (2008) Effect of protein, fat, carbohydrate and fibre on gastrointestinal peptide release in humans. Regul Pept Aug 149, 70-78.

32. Mansour A, Hesseini S, Larijani B, et al. (2013) Nutrients related to GLP1 secretory responses. Nutrition 29, 813-820.

33. Oesch S, Ruegg C, Fischer B, et al. (2006) Effect of gastric distension prior to eating on food intake and feelings of satiety in humans. Physiol Behav 87, 903-910.

34. Adrian TE, Ferri GL, Bacarese-Hamilton AJ, et al. (1985) Human distribution and release of a putative new gut hormone, peptide YY. Gastroenterology 89, 1070-1077.

35. Vozzo R, Baker B, Wittert GA, et al. (2002) Glycemic, hormone, and appetite responses to monosaccharide ingestion in patients with type 2 diabetes. Metabolism 51, 949-957.

36. Teff KL, Elliot S, Tschöp M, et al. (2004) Dietary fructose reduces circulating insulin and leptin attenuates postprandial suppression of ghrelin, and increases triglycerides in women. J Clin Endocrinol Metab 89, 2963-2972.

37. Ebert R \& Creutzfeldt W (1980) Decreased GIP through impairment of absorption. Front Horm Res 7, 192-201.

38. Alvarado F (1967) Hypothesis for the interaction of phlorizin and phloretin with membrane carriers for sugars. Biochim Biophys Acta 135, 483-495.

39. Dao TMA, Waget A, Klopp P, et al. (2011) Resveratrol increases glucose induced GLP-1 secretion in mice: a mechanism which contributes to the glycemic control. PLOS ONE 6, e20700

40. Hill BR, Rolls BJ, Roe LS, et al. (2013) Ghrelin and peptide YY increase with weight loss during a 12-month intervention to reduce dietary energy density in obese women. Peptides 49, 138-144.

41. Le Roux CW, Aylwin SJ, Batterham RL, et al. (2006) Gut hormone profiles following bariatric surgery favor an anorectic state, facilitate weight loss, and improve metabolic parameters. Ann Surg 243, 108-114.

42. Korner J, Besslerb M, Inabnetb W, et al. (2007) Exaggerated glucagon-like peptide-1 and blunted glucose-dependent insulinotropic peptide secretion are associated with Rouxen-Y gastric bypass but not adjustable gastric banding. Surg Obes Relat Dis 3, 597-601.

43. Kelly KR, Brooks LM, Solomon TPJ, et al. (2009) The glucose-dependent insulinotropic polypeptide and diet in obesity glucose-stimulated insulin response to exercise training. Am J Physiol Endocrinol Metab 296, E1269-E1274.

44. Solomon TPJ, Haus JM, Kelly KR, et al. (2010) A lowglycemic index diet combined with exercise reduces insulin resistance, postprandial hyperinsulinemia, and glucosedependent insulinotropic polypeptide responses in obese, prediabetic humans. Am J Clin Nutr 92, 1359-1368.

45. Yabe D \& Seino Y (2013) Incretin actions beyond the pancreas: lessons from knockout mice. Curr Opin Pharmacol 13, 946-953.

46. Seino Y \& Yabe D (2013) Glucose-dependent insulinotropic polypeptide and glucagon-like peptide 1: incretin actions beyond the pancreas. J Diabetes Investig 4, 108-130.

47. Green SM, Delargy HJ, Joanes D, et al. (1997) A satiety quotient: a formulation to assess the satiating effect of food. Appetite 29, 291-304.

48. Batterham RL, Heffron H, Kapoor S, et al. (2006) Critical role for peptide YY in protein-mediated satiation and bodyweight regulation. Cell Metab 4, 223-233.

49. Batterham RL, Cowley MA, Small CJ, et al. (2002) Gut hormone $\mathrm{PYY}_{3-36}$ physiologically inhibits food intake. Nature 418, 650-654.

50. Wishart JM, Horowitz M, Morris HA, et al. (1998) Relation between gastric emptying of glucose and plasma concentrations of glucagon-like peptide-1. Peptides 19, 1049-1053.

51. Cordain L, Eaton SB, Miller JB, et al. (2005) The paradoxical nature of hunter-gatherer diets: meat-based, yet nonatherogenic. Eur J Clin Nutr 56, Suppl. 1, S42-S52.

52. Barr SB \& Wright JC (2010) Postprandial energy expenditure in whole-food and processed-food meals: implications for daily energy expenditure. Food Nutr Res 54, 5144-5152.

53. Trigueros L, Peña S, Ugidos AV, et al. (2013) Food ingredients as anti-obesity agents: a review. Crit Rev Food Sci Nutr 53, 929-942.

54. Prentice AM \& Jebb SA (2003) Fast foods, energy density and obesity: a possible mechanistic link. Obes Rev 4, 187-194. 